\title{
A Study of Perfluorocarboxylate Ester Solvents for Lithium Ion Battery Electrolytes
}

Tyler M. Fears ${ }^{\mathrm{a}, \mathrm{b}, \dagger, *}$, Robert L. Sacci ${ }^{\mathrm{b}}$, Jeffrey G. Winiarz ${ }^{\mathrm{a}}$, Helmut Kaiser ${ }^{\mathrm{c}, \mathrm{d}}$, Haskell Taub ${ }^{\mathrm{c}, \mathrm{d}}$, Gabriel M. Veith ${ }^{\mathrm{b}, *}$

${ }^{a}$ Department of Chemistry, Missouri University of Science and Technology, $400 \mathrm{~W} .11^{\text {th }}$ St., Rolla, MO 65409, USA

${ }^{\mathrm{b}}$ Materials Science and Technology Division, Oak Ridge National Laboratory, 1 Bethel Valley Rd., Oak Ridge, TN, 37830, USA

${ }^{\mathrm{c}}$ University of Missouri Research Reactor, University of Missouri, 1513 Research Park Dr., Columbia, MO 65211, USA

${ }^{\mathrm{d}}$ Department of Physics and Astronomy, University of Missouri, Columbia, MO 65211, USA

${ }^{\dagger}$ U.S. Department of Energy, Office of Science Graduate Student Research Program Fellow, Oak Ridge National Laboratory

*Corresponding author

Email address: tmf9rc@mst.edu (T.M. Fears)

Email address: veithgm@ ornl.gov (G.M. Veith)

\begin{abstract}
Several high-purity methyl perfluorocarboxylates were prepared (>99.5\% purity by mole) and investigated as potential fluorine-rich electrolyte solvents in Li-ion batteries. The most conductive electrolyte, 0.1 M lithium bis(trifluoromethanesulfonyl)imide (LiTFSI) in dimethyl perfluoroglutarate $\left(\mathrm{PF}_{2}\right)$ (ionic conductivity $\left.=1.87 \times 10^{-2} \mathrm{mS} \mathrm{cm}^{-1}\right)$, is investigated in Si thin-film half-cells. The solidelectrolyte-interphase (SEI) formed by the PF5M 2 electrolyte is composed of similar organic and inorganic moieties and at comparable concentrations as those formed by ethylene carbonate/dimethyl carbonate electrolytes containing $\mathrm{LiPF}_{6}$ and LiTFSI salts. However, the SEI formed by the PF5M electrolyte undergoes reversible electrochemical defluorination, contributing to the reversible capacity
\end{abstract}


of the cell and compensating in part for capacity fade in the Si electrode. While far from ideal these electrolytes provide an opportunity to further develop predictions of suitable fluorinated molecules for use in battery solvents.

Keywords: SEI, LiTFSI, silicon thin-film, fluorinated electrolyte 


\section{Introduction:}

The fluorination of organic electrolyte components typically decreases the energy (increases the molecular electrostatic potential) of both the highest occupied molecular orbital (HOMO) and lowest unoccupied molecular orbital (LUMO), shifting the usable voltage window of electrolyte components to higher potentials [1-6]. This shift increases the stability to oxidative decomposition at the cathode but decreases stability to reductive decomposition at the anode. By controlling the oxidation and reduction potentials of each species in the electrolyte, one can theoretically control which species decompose at each electrode during the initial discharge cycle and fine-tune the properties of the solid-electrolyte-interphase (SEI), which plays a vital role in extending the lifetime of Li-ion batteries $[5-10]$.

Zhang et al. have shown that electrolytes composed entirely of fluorinated components are capable of supporting high-voltage $(>5.0 \mathrm{~V})$ Li-ion chemistry with minimal electrolyte degradation [1] and demonstrated that passivation issues with low-voltage anode materials can be overcome with the judicious use of fluorinated additives [2]. For example, the use of fluoroethylene carbonate (FEC) as an electrolyte additive has been shown to form a dense, robust, polymeric SEI that ameliorates fade in Si electrodes caused by fracture due to large volume changes during Li alloying and dealloying [4, 10-12].

To better understand the role of fluorinated species in Li-ion battery chemistry, a series of methyl perfluorocarboxylate esters (Fig. 1) were prepared and their electrochemical performance investigated. We observe that the conductivity in these neat solvents is limited largely by $\mathrm{Li}^{+}$salt solubility $(\leq 0.1 \mathrm{M})$. The electrochemical properties of the most conductive electrolyte were studied using idealized Si thin-film half-cells. We observe via X-ray photoelectron spectroscopy (XPS) that the SEI formed by this perfluorocarboxylate electrolyte on a Si electrode is composed of chemical 
moieties, e.g., organic carbonates and LiF, similar to those formed by traditional carbonate-based electrolytes at remarkably similar concentrations. However, electrochemical defluorination, wellknown in poly(tetrafluoroethylene) (PTFE) [13, 14], in combination with the high reduction potential (1.0-1.5 V) of the fluorinated solvent prevents effective electrode passivation, limiting the use of such fluorine-rich species as neat electrolyte solvents in Li-ion battery cells that require extended cycling.

Beyond adjusting the stability window, lowering the flammability $[6,15]$, and improving the SEI characteristics of common electrolytes, fluorinated organic compounds are also one family of solvents that can be largely hydrogen-free. This lack of $\mathrm{H}$ makes them prime candidates for alternative solvents in in situ neutron scattering experiments, where it is desirable to minimize the background signal due to incoherent scattering from ${ }^{1} \mathrm{H}$ [16-24].

\section{Materials and Methods:}

All reagents were used as received unless otherwise noted. Those used in Li-ion battery cells were stored in a dry Ar glovebox $\left(<5.0 \mathrm{ppm} \mathrm{O}_{2},<100 \mathrm{ppb} \mathrm{H}_{2} \mathrm{O}\right)$ prior to cell fabrication.

The perfluorocarboxylates investigated here will be referenced according to the shorthand $\mathrm{PF} n \mathrm{O}_{x} Z_{y}$, where $n$ is the number of carbons on the perfluorocarboxylate, $x$ is the number of ethereal oxygens in the perfluorocarboxylate, $Z$ identifies the terminal group (A for carboxylic acid and $\mathrm{M}$ for methyl carboxylate), and $y$ is the number of terminal groups.

\subsection{Perfluorocarboxylate Esterification:}

Perfluorobutyric acid (PF4A) (Acros, 99\%), perfluoroheptanoic acid (PF7A) (Alfa Aesar, 98+\%), perfluorononanoic acid (PF9A) (Alfa Aesar, 97\%), perfluoroglutaric acid (PF5A $)$ (Exfluor, 98\%), and perfluoro-3,6,9-trioxaundane-1,11-dioic acid $\left(\mathrm{PF}_{3} \mathrm{~A}_{2}\right)$ (Exfluor, 98\%) were esterified with methanol (MeOH) (Sigma-Aldrich, $\geq 99.8 \%$ ) to form the corresponding methyl esters, PF4M, PF7M, PF9M, PF5M 2 , and PF8O3M 2 (Fig. 1) respectively (Scheme 1). 
In a typical synthesis, $25 \mathrm{mmol}$ perfluorocarboxylic acid was dissolved in $50 \mathrm{mmol} \mathrm{MeOH}$ in a $20 \mathrm{~mL}$ scintillation vial. $\mathrm{HCl}$, prepared by passing concentrated aqueous $\mathrm{HCl}$ (Sigma-Aldrich, 37\%) vapor through a Drierite (Sigma-Aldrich) column, was bubbled through the solution, while stirring with a PTFE stir bar, until it became turbid. This solution was then sealed and stirred overnight. After allowing the reaction mixture to settle into two phases, the lower, colorless layer was collected and transferred to a $50 \mathrm{~mL}$ round-bottom flask and distilled under dry $\mathrm{N}_{2}$ (PF4M, B.P. $=80^{\circ} \mathrm{C}$; PF7M, B.P. $\left.=140^{\circ} \mathrm{C}\right)$ or vacuum $\left(\mathrm{PF9M}\right.$, B.P. $=140^{\circ} \mathrm{C} ; \mathrm{PF}_{2}$, B.P. $=120^{\circ} \mathrm{C} ; \mathrm{PF} \mathrm{O} 3 \mathrm{M}_{2}$, B.P. $\left.=160^{\circ} \mathrm{C}\right)$ as appropriate. For dicarboxylic acid esters, $100 \mathrm{mmol} \mathrm{MeOH}$ was used.

${ }^{1} \mathrm{H}(400 \mathrm{MHz})$ nuclear magnetic resonance (NMR) and ${ }^{13} \mathrm{C}(100 \mathrm{MHz}) \mathrm{NMR}$ with inversegated ${ }^{1} \mathrm{H}$ decoupling were performed on a Varian Unity Inova and used to verify ester synthesis. Purity was determined using the integral of the $\mathrm{CH}_{3}$ peak in the ${ }^{1} \mathrm{H}$ spectrum for the ester and trace $\mathrm{MeOH}$, the only detectable impurity (ester: $4.0 \mathrm{ppm}$ in ${ }^{1} \mathrm{H}$ and $54.2 \mathrm{ppm}$ in ${ }^{13} \mathrm{C}$ vs. tetramethylsilane (TMS); MeOH: 3.3 ppm in ${ }^{1} \mathrm{H}$ and $48.6 \mathrm{ppm}$ in ${ }^{13} \mathrm{C}$ vs. TMS).

As-distilled esters were dried by storing over 3A molecular sieves (Alfa Aesar) in an Ar-filled glovebox for two weeks. A series of dry electrolyte salts $\left(\mathrm{LiPF}_{6}, \mathrm{LiClO}_{4}\right.$, lithium triflate, lithium bis(oxalato)borate) was investigated, and only LiTFSI (3M, Battery Grade) was found to be appreciably soluble in the synthesized esters.

\subsection{Si Thin Film Fabrication:}

$\mathrm{Si}$ thin-film electrodes were prepared via radio-frequency (RF) magnetron sputtering using an undoped Si target (99.999\%, Kurt J. Lesker) under Ar (99.9995\%, Air Liquide) at 7.5 mTorr and 90 W RF power. The deposition rate was determined to be $8 \mathrm{~nm} / \mathrm{min}$ using a quartz crystal microbalance 
(Inficon). Si was deposited for $10 \mathrm{~min}$ onto a rough electrochemical-grade $\mathrm{Cu}$ foil (Oak-Mitsui) and cut into 13-mm diameter electrodes with a kerfless punch (EL-CELL).

\subsection{Electrochemical Characterization:}

Four electrolytes were evaluated in this work: $1.2 \mathrm{M} \mathrm{LiPF} 6$ in 3:7 (by volume) ethylene carbonate/dimethyl carbonate (EC/DMC) (BASF), 0.1 M LiTFSI in 3:7 EC/DMC (Reagent Grade solvents, Aldrich, dried over 3A molecular sieves, <1 ppm $\mathrm{H}_{2} \mathrm{O}$ ), $0.1 \mathrm{M} \mathrm{LiTFSI}$ in PF5M 2 , and saturated $0.1 \mathrm{M}$ LiTFSI in $\mathrm{PF}_{3} \mathrm{O}_{3} \mathrm{M}_{2}$. Given that the $\mathrm{PF5} \mathrm{M}_{2}$-based electrolyte possessed the highest conductivity of the perfluocarboxylate esters, it was exclusively used for electrochemical cycling studies.

Impedance spectroscopy was performed using a Biologic SP200 with an Accumet two-point Pt conductivity probe (\#13-620-155) possessing a $1.0 \mathrm{~cm}^{-1}$ cell constant in an Ar-filled glovebox. Electrolyte conductivity was obtained by fitting the impedance spectra to a typical RC circuit.

CR2023 stainless steel coin cells (Pred Materials) were prepared using Li ribbon (99.9\% Alfa Aesar), porous polypropylene separators (Treopore) wetted with electrolyte, and 13-mm diameter Si thin-film electrodes. Coin cells were galvanostatically cycled on a Maccor 4000 battery cycler at 10 $\mu \mathrm{A}$ with voltage cutoffs $0.07 \mathrm{~V}$ upon lithiation and $2.5 \mathrm{~V}$ upon delithiation with a 10 min equilibration

period between steps, corresponding to a nominal cycling rate of $\mathrm{C} / 10$. Rate performance was probed using galvanostatic currents of $5 \mu \mathrm{A}(\mathrm{C} / 20), 10 \mu \mathrm{A}(\mathrm{C} / 10), 20 \mu \mathrm{A}(\mathrm{C} / 5)$, and $50 \mu \mathrm{A}(\mathrm{C} / 2)$. Capacity data were normalized to the first delithiation capacity for each cell to account for slight variability in thin film thickness across the $\mathrm{Cu}$ foil.

\subsection{Ex situ Analysis of Cycled Electrodes:}


After galvanostatic cycling, coin cells were transferred into an Ar-filled glovebox for decrimping. Electrodes were rinsed with $2 \mathrm{~mL}$ DMC to remove excess electrolyte, dried under vacuum, and sectioned for ex situ analysis of insoluble SEI components.

Attenuated total reflectance infrared absorption (ATR-IR) spectroscopy was performed on the PF5M $\mathrm{M}_{2}$-based electrolyte as prepared and on residue collected from a separator after extensive cycling (500 cycles at C/5) without exposure to air. ATR-IR was performed on a Bio-Rad 575c with a $4 \mathrm{~mm} \times$

$4 \mathrm{~mm}$ diamond ATR crystal (Golden Gate, Specac) with a reactive sample anvil and $\mathrm{KBr}$ beam splitter.

XPS data were collected on Si electrodes cycled in $0.1 \mathrm{M}$ LiTFSI in $\mathrm{PF}_{2} \mathrm{M}_{2}$ electrolyte to various states of charge (SOC). Electrodes cycled in 1.2 $\mathrm{M} \mathrm{LiPF}_{6}$ in 3:7 EC/DMC and 0.1 M LiTFSI in 3:7 EC-DMC were stopped at their 7th discharge $(0.07 \mathrm{~V})$ for comparison. Electrodes were transferred from the glovebox to the XPS sample stage under vacuum in a specially developed transfer chamber to prevent errant decomposition upon exposure to air. XPS data were collected on a PHI 3056 with an $\mathrm{Al}$ anode source operating at $15 \mathrm{kV}$ and $23.3 \mathrm{~mA}$. High-resolution spectra were collected using a pass energy of $5.85 \mathrm{eV}$ with $0.05 \mathrm{eV}$ steps. Peak fitting and quantitative elemental analysis was performed using the PHI Multipak analysis suite and standard sensitivity factors. Binding energies were referenced to the $\mathrm{C} 1 \mathrm{~s} \mathrm{C}-\mathrm{H}$ peak $(284.8 \mathrm{eV})$. Intensity (counts per second) was normalized to the measured total atomic composition to prevent systematic errors in signal intensity.

\section{Results:}

\subsection{Ester Physical Properties:}

Specific perfluorocarboxylate esters were chosen to investigate the effects of perfluorinated chain length, mono- versus dicarboxylate esters, and the effect of ethereal functional groups (Fig. 1). 
Despite the relatively low purity of the carboxylic acid starting reagents, ${ }^{13} \mathrm{C}$ and ${ }^{1} \mathrm{H}$ NMR revealed that the esterified products were highly pure: $0.5 \mathrm{~mol} \% \mathrm{MeOH}$ was detected in PF4M and $<0.1 \mathrm{~mol} \%$ $\mathrm{MeOH}$ in all other cases. This trend is explained by the fact that increasing the boiling point of an ester allows easier separation from volatile compounds; esters that were vacuum distilled above 100 ${ }^{\circ} \mathrm{C}$ can be held under vacuum at room temperature with no observable sample loss and contained no detectable methanol impurity. No additional impurities were detected above $0.01 \mathrm{~mol} \%$ via ${ }^{1} \mathrm{H}$ or ${ }^{13} \mathrm{C}$ NMR in any sample. All distilled esters were colorless; however, the upper phase discarded during synthesis was often pale yellow. We believe that impurities in the starting materials dissolve selectively in the $\mathrm{MeOH} / \mathrm{H}_{2} \mathrm{O} / \mathrm{HCl}$ phase, resulting in high product purity without excessive processing.

LiTFSI solubility in the synthesized esters qualitatively follows the trend $\mathrm{PF}_{2} \mathrm{M}_{2} \geq 0.1$ $\mathrm{M}>>\mathrm{PF}_{3} \mathrm{O}_{3} \mathrm{M}_{2} \geq \mathrm{PF} 4 \mathrm{M}>\mathrm{PF} 7 \mathrm{M}>\mathrm{PF} 9 \mathrm{M}$. Solubility appears to depend primarily upon the molar density of ester functional groups $\left(\mathrm{PF}_{2} \mathrm{M}_{2}=11.1 \mathrm{M} ; \mathrm{PF}_{3} \mathrm{M}_{2}=6.78 \mathrm{M} ; \mathrm{PF} 4 \mathrm{M}=6.45 \mathrm{M} ; \mathrm{PF} 7 \mathrm{M}=4.39 \mathrm{M}\right.$; PF9M = $3.62 \mathrm{M})$, consistent with previous reports [15]. It appears that the perfluorinated ether functionality, as in $\mathrm{PF}_{3} \mathrm{O}_{3} \mathrm{M}_{2}$, contributes negligibly to solubility, presumably due to the low net polarity of competing $\mathrm{C}-\mathrm{O}$ and $\mathrm{C}-\mathrm{F}$ dipoles. The low solubility of LiTFSI limits electrolyte conductivity (Table 1). As a result, only PF5M 2 can be utilized as a neat electrolyte solvent. While the conductivity of $0.1 \mathrm{M}$ LiTFSI in PF5M 2 is inferior to both EC-DMC-based electrolytes, it is sufficient for operation at the low current densities necessary to investigate SEI formation on thin-film electrodes.

\subsection{Galvanostatic Cycling of Si Anode Half-Cells:}

Fig. 2 (left) shows the normalized galvanostatic discharge (Si reduction/lithiation) and charge (Si oxidation/delithiation) curves for $\mathrm{Si}$ thin film half-cells as a function of electrolyte composition 
and cycling rate up to 25 cycles. Based on a theoretical Si capacity of $3578 \mathrm{mAh} \mathrm{g}^{-1}\left(\mathrm{Li}_{15} \mathrm{Si}_{4}\right)$ and a target film thickness of $80 \mathrm{~nm}$, these electrodes are expected to possess a capacity of $90 \mu \mathrm{Ah}$; however, due to electrolyte limitations and non-uniform Si deposition, due to thinning at the edges during film growth from the larger deposition distances, the capacities are highly variable. To account for these effects, the capacity was normalized to that of the first delithiation capacity, which depends only upon the total Si mass and degree of lithiation. As a result the discharge profiles are plotted with respect to $100 \%$ of the discharge capacity. The actual capacities are reported within the figures. The advantage of this approach is that we can more clearly identify changes in capacity with cycling. The corresponding differential capacity curves (Fig. 2, right) highlight the major electrochemical reactions taking place: reversible lithiation $(\dagger)$, irreversible lithiation $(\dagger)$, and SEI formation $(*)$. Lithiation steps occur at 0.25 and $0.10 \mathrm{~V}$ in the carbonate-based electrolytes (Fig. 2, $\dagger$ ). In the PF5M $\mathrm{M}_{2}$ electrolyte, lithiation occurs at lower potentials, due to appreciable resistive losses. Increasing cycling rate exacerbates this potential drop. At $\mathrm{C} / 5$, only a single lithiation step is apparent above the $0.07 \mathrm{~V}$ cutoff.

All electrolytes exhibited two major irreversible reduction features at $0.5 \mathrm{~V}$ and $0.3 \mathrm{~V}$ during the first cycle (Fig. 2, $\$$ ). The fact that the reduction potentials for these features are independent of the electrolyte used is evidence that these peaks are related to electrode-rather than electrolyte-chemistry. Work by Mullins et al. on partially oxidized Si electrodes suggests that the sharp reduction feature around $0.5 \mathrm{~V}$ is related to the lithiation of $\mathrm{SiO}_{\mathrm{x}}$ while the feature at $0.3 \mathrm{~V}$ is related to the irreversible lithiation of $\mathrm{Si}^{0}$ [25]. The capacity corresponding to the $\mathrm{SiO}_{\mathrm{x}}$ peak is $2.8 \pm$ $0.2 \mu \mathrm{Ah}$, equivalent to a $4.5 \pm 0.3 \mathrm{~nm}$ layer of $\mathrm{SiO}_{2}\left(4 \mathrm{Li}+\mathrm{SiO}_{2} \rightarrow \mathrm{Si}+2 \mathrm{Li}_{2} \mathrm{O}, 1.59 \mathrm{~nm}-\mu \mathrm{Ah}^{-1}\right.$ for 13 mm electrodes). The fact that the capacity of this feature is independent of the bulk lithiation capacity 
is consistent with a surface phenomenon. Because the $\mathrm{Cu}$ substrate is rough, resulting in an increased surface area, this calculation overestimates the thickness of a $\mathrm{SiO}_{2}$ film. The location of the reduction peak at $0.3 \mathrm{~V}$ prevents accurate integration. However, beyond asserting that these two reduction peaks are unique to the electrode and not associated with electrolyte chemistry, a detailed interpretation of these features is beyond the scope of this study.

SEI formation is most likely related to small irreversible peaks that can be seen in the differential capacity curve insets (Fig. 2, *). Specifically, carbonate-based electrolytes (Fig. 2F and 2G) show reduction peaks at 1.75 and $0.75 \mathrm{~V}$, while the $\mathrm{PF} \mathrm{M}_{2}$ electrolyte (Fig. 2H, 2I, and 2J) shows a pair of broad peaks between 1.5 and $1.0 \mathrm{~V}$. These features disappear after the first cycle, but similar features reappear around cycle 10 in the $\mathrm{PF}^{2} \mathrm{M}_{2}$ electrolyte and grow steadily in intensity, suggesting that the SEI formed in this electrolyte does not effectively passivate the electrode.

The charge-discharge curves for the $\mathrm{PF} \mathrm{M}_{2}$ electrolyte (Fig. 2C, 2D, and 2E) change in shape in later cycles. The linear region in the charge ( $\mathrm{Si}$ delithiation) curve adopts a gentler slope, compensating in part for a decrease in the capacity of the Si lithiation peaks at $0.25 \mathrm{~V}$ and $0.10 \mathrm{~V}$ (Fig. 2H, 2I, and 2J), leading to a relatively stable capacity. Given that the change in the charge curve coincides with the reemergence of the SEI reduction peaks during discharge (Fig. 2H, 2I, and 2J, *), it is likely that these features are due to electrochemical reactions within the SEI. The fact that these changes do not occur in the carbonate electrolytes is further evidence that these changes are related to $\mathrm{PF}_{\mathrm{M}}$ and not electrode chemistry.

Si anodes cycled with the PF5M 2 electrolyte suffer a $\sim 12 \%$ loss in capacity after the first cycle (Fig. 3A) but regain it over the next 5 cycles. The initial loss in capacity is attributed to thermodynamic changes in the lithiation potential, e.g., structural relaxation, and increased cell resistance due to SEI formation during the first few cycles. Because high resistive losses due to the 
low conductivity of the electrolyte place the lithiation potential very near the voltage cutoff, electrodes cycled in the $\mathrm{PF} \mathrm{M}_{2}$ electrolyte are exquisitely sensitive to changes in the lithiation thermodynamics and cell resistance. The high cell resistance is illustrated by the greater voltage shift in the differential capacity curves with higher cycling rates (lower lithiation voltage and higher delithiation voltage) (Fig. 2H, 2I, and 2J). At C/2 these small changes are enough to move the lithiation potential below the voltage cutoff, resulting in immediate and catastrophic capacity fade (Fig. 3A).

The initial drop and subsequent recovery in the delithiation capacity appears invariant when normalized to the initial delithiation capacity (Fig. 3A), implying that the reaction(s) responsible for this capacity are associated with the bulk of the Si film, consistent with silicon lithiation. By contrast, the irreversible reduction in capacity during lithiation appears invariant at low currents $(\mathrm{C} / 10$ and C/20) with respect to absolute current (Fig. 3B), suggesting a surface phenomenon. At high current densities $(\mathrm{C} / 2)$, this irreversible loss drops to zero after only a few cycles, reflective of kinetic limitations on the reaction, consistent with electrochemical reactions taking place away from the $\mathrm{Si}$ electrode, i.e., electrolyte decomposition instead of Si lithiation. The observed irreversible capacity is qualitatively consistent with the magnitude of reduction peaks attributed to SEI formation (Fig. 2H, 2I, and $\mathbf{2 J} *$ ).

Si anodes cycled in the carbonate electrolytes do not show the early capacity loss-recovery behavior and fade much more quickly than those cycled in the $\mathrm{PF}^{2} \mathrm{M}_{2}$ electrolyte (Fig. 3A). This latter effect is attributable to the higher conductivity of the carbonate electrolytes which allows for deep lithiation of the $\mathrm{Si}$ electrode, where extreme volume changes speed $\mathrm{Si}$ fracture, the primary source of capacity fade in Si electrodes [11, 26, 27]. The irreversible reductive capacity (Fig. 3B) of electrodes cycled in the carbonate electrolytes is relatively constant (2-3 $\mu \mathrm{Ah})$ and much less than that 
observed in the $\mathrm{PF}_{2} \mathrm{M}_{2}$ electrolyte ( $\left.>12 \mu \mathrm{Ah}\right)$, implying that electrochemical decomposition of the electrolyte is more significant in the $\mathrm{PF} \mathrm{M}_{2}$ electrolyte.

\subsection{ATR-IR of Soluble Electrolyte Decomposition Products:}

To investigate soluble species produced as a result of electrolyte decomposition, ATR-IR was performed on the PF5M $\mathrm{M}_{2}$ electrolyte before and after extensive cycling (Fig. 4). ATR-IR spectra show no major changes in the $\mathrm{PF}_{2} \mathrm{M}_{2}$ electrolyte with extended cycling (500 cycles at C/5) except for a small feature that appears around $1700 \mathrm{~cm}^{-1}$, consistent with a carbonyl stretch. This stretch is most likely due to a partially soluble lithium perfluorocarboxylate created via electrochemical deesterification of $\mathrm{PF}_{2} \mathrm{M}_{2}$ during SEI formation (Scheme 2). The lack of changes in the regions of 3000

$\mathrm{cm}^{-1}$ to $3600 \mathrm{~cm}^{-1}(\mathrm{COOH}, \mathrm{OH})$ and $2850 \mathrm{~cm}^{-1}$ to $3000 \mathrm{~cm}^{-1}(\mathrm{CH})$ suggest that no protic or alkyl species are formed at detectable levels. Unfortunately, since the $\mathrm{TFSI}^{-}$anion is undetectable due to its low concentration and interference from $\mathrm{PF} \mathrm{M}_{2}$, it is unlikely that any of its decomposition products, if decomposition occurs, would be observed.

\subsection{XPS of SEIs Formed on Si Anodes:}

High resolution XPS data were collected on Si electrodes $(0.07 \mathrm{~V})$ after 7 lithiations with $1.2 \mathrm{M} \mathrm{LiPF}_{6}$ in 3:7 EC/DMC and 0.1 M LiTFSI in 3:7 EC/DMC and compared to one lithiated twice in $0.1 \mathrm{M}$ LiTFSI in PF5M $\mathrm{M}_{2}$ to investigate the effects of both electrolyte salt and solvent on SEI characteristics. Despite their significantly differing chemistries, SEIs formed from $\mathrm{PF}_{\mathrm{M}} \mathrm{M}_{2}$-based and carbonate-based electrolytes are remarkably similar (Fig. 5), containing $\mathrm{LiF}$ and $\mathrm{Li}_{2} \mathrm{CO}_{3}$ in addition to organic carbonates (C 1s: $\mathbf{C O}_{3}, 289 \mathrm{eV}$; O 1s: $\mathbf{C}=\mathbf{O}, 532 \mathrm{eV}$, and C-O, $\left.533 \mathrm{eV}\right)$, carboxylates $\left(\mathrm{C}\right.$ 1s: $\mathbf{C O}_{2}, 289$ $\mathrm{eV}$; O 1s: $\mathbf{C}=\mathbf{O}$ and $\mathbf{C}-\mathbf{O})$, ethers/esters $(\mathrm{C} 1 \mathrm{~s}: \mathbf{C O}, 285.5 \mathrm{eV}$; O 1s: C-O), and fluorides (C 1s: $\mathbf{C F}$, 
$287 \mathrm{eV}$; F1s: CF $689 \mathrm{eV}$ ) in similar concentrations. The greatest compositional differences between the three electrolyte systems is the presence of the PF peak for the $\mathrm{LiPF}_{6}-\mathrm{EC} / \mathrm{DMC}$ electrolyte (F 1s, $688 \mathrm{eV})$ and the absence of the $\mathrm{Li}_{2} \mathrm{O}$ peak for the $\mathrm{PF} \mathrm{M}_{2}$ electrolyte $(\mathrm{O} 1 \mathrm{~s}, 528 \mathrm{eV}$, and $\mathrm{Li} 1 \mathrm{~s}, 54 \mathrm{eV})$.

The P $2 p$ and $\mathrm{N} 1$ s spectra (not shown) indicate the presence of 1.6 at.\% $\mathrm{P}$ in the electrolyte with $\mathrm{LiPF}_{6}$ and 0.2 at.\% $\mathrm{N}$ in the electrolytes with LiTFSI, suggesting that decomposition products of $\mathrm{PF}_{6}^{-}$are a more significant (though still small) part of the SEI formed in $\mathrm{LiPF}_{6}$-based electrolytes when compared to those utilizing LiTFSI. However, because TFSI ${ }^{-}$is the only source of $\mathrm{F}$ in the 0.1 M LiTFSI in EC/DMC electrolyte, the presence of LiF at a significant concentration (10.0 at.\% of the SEI) implies that TFSI ${ }^{-}$decomposition occurs readily, possibly with the formation of soluble $\mathrm{S}$ and $\mathrm{N}$ species.

To investigate the compositional changes of the $\mathrm{PF} \mathrm{M}_{2}$ SEI during formation, XPS data (Fig. 6) were collected at several SOCs (Fig. 7). While $\mathrm{Li}_{2} \mathrm{O}$ appears to form only in the carbonate electrolytes (Fig. 5), analysis of the SEI formed by the PF5M $\mathrm{M}_{2}$ electrolyte during the first cycle (Fig. 6) does show the formation of $\mathrm{Li}_{2} \mathrm{O}$. This finding is consistent with the observation that $\mathrm{Li}_{2} \mathrm{O}$ is produced from the lithiation of $\mathrm{SiO}_{\mathrm{x}}$ at the electrode surface [10, 28]. Continued SEI growth buries this interface, reducing its intensity and making it undetectable. The fact that it is detectable in electrodes cycled with the carbonate electrolytes but not the $\mathrm{PF} 5 \mathrm{M}_{2}$ electrolyte after repeated cycling suggests that the SEI formed by the $\mathrm{PF} \mathrm{M}_{2}$ electrolyte is thicker than that formed by the carbonate electrolytes, consistent with the increased and continued electrolyte decomposition observed in the $\mathrm{PF} \mathrm{M}_{2}$ electrolyte during galvanostatic cycling (Fig. 2).

XPS data collected for the bare Si electrode and electrode held at open circuit voltage (OCV) vs. $\mathrm{Li}^{2} \mathrm{Li}^{+}$for 10 min under the $\mathrm{PF} \mathrm{M}_{2}$ shows only adventitious $\mathrm{C} 1 \mathrm{~s}$ and $\mathrm{F} 1 \mathrm{~s}$ signals, indicating no SEI is formed in the absence of a reduction current. A slight broadening and increase in the binding 
energy of the $103 \mathrm{eV}$ peak in the $\mathrm{Si} 2 \mathrm{p}$ peak is consistent with the conversion of $\mathrm{SiO}_{2}$ to $\mathrm{SiO}_{2-\mathrm{x}} \mathrm{F}_{2 \mathrm{x}}$, suggesting that some chemical reaction does take place before SEI formation. In both cases, the peak areas indicate that $27 \%$ of the $\mathrm{Si}$ within the sampling depth is $\mathrm{SiO}_{2} / \mathrm{SiO}_{2-\mathrm{x}} \mathrm{F}_{2 \mathrm{x}}$. Assuming a sampling depth of $10 \pm 2 \mathrm{~nm}$, we estimate a $\mathrm{SiO}_{2}$ thickness of $5.4 \pm 1.1 \mathrm{~nm}$, consistent with that determined from the $\mathrm{SiO}_{2}$ lithiation capacity (Fig. 2, 0.5 V). These $\mathrm{Si}$ peaks can be used as a qualitative estimate for the SEI thickness (lower intensity implies a thicker SEI). Using this measure, we can see that the SEI forms above $0.6 \mathrm{~V}$ and continues to grow during lithiation. It then appears to shrink during delithiation and swell during lithiation. This "breathing" phenomenon has been previously observed through similar techniques [22, 23, 28].

XPS data show that the initial formation of the SEI in the PF5M 2 electrolyte occurred between OCV and 0.6 V upon discharge, suggesting that the small electrochemical reaction(s) around 1.5-1.0 V (Fig. 2H, 2I, and 2J, *) corresponds to SEI formation. This initial SEI appears to be composed primarily of fluorinated carboxylates $\left(\mathrm{CO}_{2}, \mathrm{CO}, \mathrm{CF}\right)$ and $\mathrm{LiF}$ (Fig. 6). Electrochemical defluorination of adjacent $\mathrm{C}-\mathrm{F}$ bonds by $\mathrm{Li}^{+}$is known to occur $(\mathrm{C}=\mathrm{C} \cdots \mathrm{LiF}: \mathrm{C} 1 \mathrm{~s}, 289 \mathrm{eV})$, meaning that the presence of $\mathrm{LiF}(\mathrm{Li} 1 \mathrm{~s}, 56 \mathrm{eV}$, and F 1s, $686 \mathrm{eV}$ ) in the initial SEI could be due to either LiTFSI decomposition, shown to occur in the carbonate electrolyte, or partial electrochemical defluorination of the perfluorocarboxylate component of the SEI (Scheme 3). The pronounced CF signal (C 1s, $287 \mathrm{eV}$, and $\mathrm{F} 1 \mathrm{~s}, 689 \mathrm{eV}$ ) disappears with additional electrochemical reduction (between 0.6 and $0.2 \mathrm{~V}$ ), indicating that electrochemical defluorination goes to completion. Upon delithiation, these peaks reappear, meaning that either additional SEI forms during delithiation or electrochemical defluorination is reversible. The intensity of the Si $2 p$ peaks makes it unlikely that any significant SEI growth takes place during delithiation, the perfluorocarboxylate defluorination must be at least partially reversible. 
After the second discharge, a significant change in the SEI composition took place, most dramatically seen in the atomic fractions (Fig. 6, bottom right). While the $\mathrm{C}$ and $\mathrm{Li}$ atomic fractions remained relatively unchanged, the $\mathrm{O}$ content increased drastically at the expense of $\mathrm{F}$. No additional soluble F compounds were detected via IR, so it is unlikely that F is lost from the SEI. Instead, we find it probable that partially soluble defluorinated carboxylate and carbonate moieties segregated towards the surface of the SEI during the cycling, increasing their observed intensity via XPS. This interpretation is consistent with the formation of a $\mathrm{CO}_{3}$ peak in the $\mathrm{C} 1 \mathrm{~s}$ spectrum $(290 \mathrm{eV})$ and the $\sim 0.3 \mathrm{eV}$ decrease in the binding energy (and slightly lower intensity) of the primary Li 1s peak. Such changes have been observed previously in other studies $[9,28]$. We are unable to explain the systematic change in the binding energy of the LiF F 1s peak, but, since the shift appears reversible $(686.0 \mathrm{eV}$ at $0.07 \mathrm{~V}$ on the first and second discharge and $685.8 \mathrm{eV}$ at $0.6 \mathrm{~V}$ and $2.5 \mathrm{~V}$ ), it may be related to the electrochemical defluorination reaction.

\section{Discussion:}

While these studies investigated a number of new battery solvent molecules we found significant similarities in the atomic and functional composition of SEIs formed from carbonate-based and perfluorocarboxylate-based electrolytes. This is surprising given the significant chemical differences between the solvent molecules indicating the SEI formation reactions drive to specific low energy chemical species, e.g. $\mathrm{LiF}, \mathrm{Li}_{2} \mathrm{CO}_{3}$ etc. These apparent similarities, though, do not prevent the systems from possessing quite different electrochemical properties, i.e., defluorination and passivation, suggesting that important subtleties in SEI composition are not captured via XPS [29]. Additionally, ex situ analysis only captures insoluble SEI components possibly missing species essential to SEI function. 
The decreased capacity fade of the Si electrodes in the PF5M 2 electrolyte (110\% (C/20), 100\% (C/10), and 90\% (C/5) compared to 75\% (0.1 M LiTFSI in EC/DMC, C/10) and 50\% (1.2 M LiPF 6 in EC/DMC, C/10) after 25 cycles) can be partially attributed to shallower lithiation and the accompanying reduction in electrode strain [11]; however, the anomalous (yet repeatable) change in the voltage profile at later cycles partially compensates for the observed capacity losses in the lithiation and delithiation peaks. This capacity is most likely related to reversible electrochemical defluorination within the SEI. Unfortunately, we believe that these reactions increase the electronic conductivity of the SEI through the formation of an extended conjugated network, inhibiting effective passivation, as evinced by the large $\left(>9.0 \mu \mathrm{Ah} / \mathrm{cm}^{2}\right)$ irreversible capacity and growth of SEI reduction peaks.

While this study focused on the use of perfluorocarboxylate esters as neat electrolyte solvents to reduce experimental complexity, there is no reason to limit their use to such simple systems. Additives, such as EC or fluorinated components, e.g., those investigated by Zhang et al. [1,2], which chelate $\mathrm{Li}^{+}$more strongly would almost certainly improve conductivity and may improve SEI stability without sacrificing beneficial properties like nonflammability, oxidative stability, and neutron transparency.

\section{Conclusion:}

Perfluorocarboxylate esters can be easily and inexpensively synthesized in high purity; however, as neat solvents, they do not possess the necessary conductivity to compete with more traditional electrolytes in commercial Li-ion batteries. Interestingly, the SEI formed from these electrolytes appears to undergo reversible electrochemical defluorination, contributing to the cycling capacity and compensating in part for fade due to electrode fracture and delamination. The low inherent stability of 
the electrolyte towards reduction, possibly combined with the electronic conductivity of an extended conjugated network formed in the SEI during electrochemical defluorination, leads to continual electrolyte decomposition. These properties may also apply to similar heavily fluorinated species proposed for next generation Li-ion electrolytes [1, 2, 5, 30, 31]. In particular the defluorination reaction, which may impart unwanted electronic conductivity in the SEI, has been shown in poly(tetrafluoroethylene) to be related to neighboring C-F bonds [13, 14], an issue that can be ameliorated with careful synthetic design.

\section{Conflicts of Interest:}

The authors declare no conflicts of interest.

\section{Acknowledgements:}

Student support and materials for ester synthesis were provided by the U.S. National Science Foundation under Grant No. DGE-1069091. Student support for the electrochemical, XPS, and ATRIR studies performed at Oak Ridge National Laboratory provided by the U.S. Department of Energy, Office of Science, Office of Workforce Development for Teachers and Scientists, Office of Science Graduate Student Research (SCGSR) program. The SCGSR program is administered by the Oak Ridge Institute for Science and Education for the DOE under contract number DE-AC05-06OR23100. The equipment, materials and technical guidance at ORNL was supported by the Materials Sciences and Engineering Division, Office of Basic Energy Sciences, U.S. Department of Energy under contract with UT-Battelle, LLC (GMV - XPS, ATR-IR, electrochemical) and the Fluid Interface Reactions, Structures, and Transport (FIRST) Center, an Energy Frontier Research Center funded by the U.S. Department of Energy, Office of Science, Office of Basic Energy Sciences (RLS - 
Conductivity, ATR-IR). T.M.F. would also like to thank Dr. C. Sotiriou-Leventis for help in formulating the perfluorocarboxylate ester synthesis.

\section{References:}

[1] Z. Zhang, L. Hu, H. Wu, W. Weng, M. Koh, P.C. Redfern, L.A. Curtiss, K. Amine, Energy \& Environmental Science, 6 (2013) 1806.

[2] L. Hu, Z. Xue, K. Amine, Z. Zhang, Journal of the Electrochemical Society, 161 (2014) A1777A1781.

[3] T. Böttcher, B. Duda, N. Kalinovich, O. Kazakova, M. Ponomarenko, K. Vlasov, M. Winter, G.V. Röschenthaler, Progress in Solid State Chemistry, 42 (2014) 202-217.

[4] X. Chen, X. Li, D. Mei, J. Feng, M.Y. Hu, J. Hu, M. Engelhard, J. Zheng, W. Xu, J. Xiao, J. Liu, J.-G. Zhang, ChemSusChem, 7 (2014) 549-554.

[5] H.Q. Pham, K.M. Nam, E.H. Hwang, Y.G. Kwon, H.M. Jung, S.W. Song, Journal of the Electrochemical Society, 161 (2014) A2002-A2011.

[6] K. Xu, Chem Rev, 114 (2014) 11503-11618.

[7] P. Verma, P. Maire, P. Novák, Electrochimica Acta, 55 (2010) 6332-6341.

[8] K.C. Klavetter, S.M. Wood, Y.-M. Lin, J.L. Snider, N.C. Davy, A.M. Chockla, D.K. Romanovicz, B.A. Korgel, J.-W. Lee, A. Heller, C.B. Mullins, Journal of Power Sources, 238 (2013) 123-136.

[9] C.K. Chan, R. Ruffo, S.S. Hong, Y. Cui, Journal of Power Sources, 189 (2009) 1132-1140.

[10] B. Philippe, R. Dedryvère, M. Gorgoi, H. Rensmo, D. Gonbeau, K. Edström, Chemistry of Materials, 25 (2013) 394-404.

[11] V. Chakrapani, F. Rusli, M.A. Filler, P.A. Kohl, Journal of Power Sources, 205 (2012) 433-438. 
[12] N. Delpuech, N. Dupré, D. Mazouzi, J. Gaubicher, P. Moreau, J.S. Bridel, D. Guyomard, B. Lestriez, Electrochemistry Communications, 33 (2013) 72-75.

[13] L. Kavan, F.P. Dousek, K. Doblhofer, Journal of Fluorine Chemistry, 55 (1991) 37-45.

[14] L. Kavan, F.P. Dousek, P. Janda, J. Weber, Chemistry of Materials, 11 (1999) 329-335.

[15] D.H. Wong, J.L. Thelen, Y. Fu, D. Devaux, A.A. Pandya, V.S. Battaglia, N.P. Balsara, J.M. DeSimone, Proc Natl Acad Sci U S A, 111 (2014) 3327-3331.

[16] I.A. Bobrikov, A.M. Balagurov, C.-W. Hu, C.-H. Lee, T.-Y. Chen, S. Deleg, D.A. Balagurov, Journal of Power Sources, 258 (2014) 356-364.

[17] O. Dolotko, A. Senyshyn, M.J. Mühlbauer, K. Nikolowski, H. Ehrenberg, Journal of Power Sources, 255 (2014) 197-203.

[18] T.C. Hansen, H. Kohlmann, Zeitschrift für anorganische und allgemeine Chemie, 640 (2014) 3044-3063.

[19] H. Liu, C.R. Fell, K. An, L. Cai, Y.S. Meng, Journal of Power Sources, 240 (2013) 772-778.

[20] M. Roberts, J.J. Biendicho, S. Hull, P. Beran, T. Gustafsson, G. Svensson, K. Edström, Journal of Power Sources, 226 (2013) 249-255.

[21] J.F. Browning, L. Baggetto, K.L. Jungjohann, Y. Wang, W.E. Tenhaeff, J.K. Keum, D.L. Wood, G.M. Veith, ACS Applied Materials \& Interfaces, 6 (2014) 18569-18576.

[22] B. Jerliu, L. Dorrer, E. Huger, G. Borchardt, R. Steitz, U. Geckle, V. Oberst, M. Bruns, O. Schneider, H. Schmidt, Physical Chemistry Chemical Physics, 15 (2013) 7777-7784.

[23] J.E. Owejan, J.P. Owejan, S.C. DeCaluwe, J.A. Dura, Chemistry of Materials, 24 (2012) 21332140.

[24] G.M. Veith, L. Baggetto, R.L. Sacci, R.R. Unocic, W.E. Tenhaeff, J.F. Browning, Chemical Communications, 50 (2014) 3081-3084. 
[25] P.R. Abel, Y.-M. Lin, H. Celio, A. Heller, C.B. Mullins, ACS Nano, 6 (2012) 2506-2516.

[26] C.K. Chan, H. Peng, G. Liu, K. Mcllwrath, X.F. Zhang, R.A. Huggins, Y. Cui, Nat Nanotechnol, 3 (2008) 31-35.

[27] Y. Oumellal, N. Delpuech, D. Mazouzi, N. Dupré, J. Gaubicher, P. Moreau, P. Soudan, B. Lestriez, D. Guyomard, Journal of Materials Chemistry, 21 (2011) 6201.

[28] B. Philippe, R. Dedryvère, J. Allouche, F. Lindgren, M. Gorgoi, H. Rensmo, D. Gonbeau, K. Edström, Chemistry of Materials, 24 (2012) 1107-1115.

[29] N. Leifer, M.C. Smart, G.K.S. Prakash, L. Gonzalez, L. Sanchez, K.A. Smith, P. Bhalla, C.P. Grey, S.G. Greenbaum, Journal of The Electrochemical Society, 158 (2011) A471.

[30] M.L. Gordin, F. Dai, S. Chen, T. Xu, J. Song, D. Tang, N. Azimi, Z. Zhang, D. Wang, ACS Appl Mater Interfaces, 6 (2014) 8006-8010.

[31] J. Kalhoff, D. Bresser, M. Bolloli, F. Alloin, J.Y. Sanchez, S. Passerini, ChemSusChem, 7 (2014) 2939-2946. 
Table 1

\begin{tabular}{cc}
\hline Electrolyte & $\begin{array}{c}\text { Conductivity } \\
\left(\mathbf{m S}-\mathbf{c m}^{-\mathbf{1}}\right)\end{array}$ \\
\hline $\begin{array}{c}1.2 \mathrm{M} \mathrm{LiPF}_{6} \\
\text { in } 3: 7 \mathrm{EC} / \mathrm{DMC}\end{array}$ & 11.0 \\
$\begin{array}{c}\text { 0.1 M LiTFSI } \\
\text { in 3:7 EC/DMC }\end{array}$ & 2.51 \\
0.1 M LiTFSI \\
in PF5M
\end{tabular}


Graphical Abstract
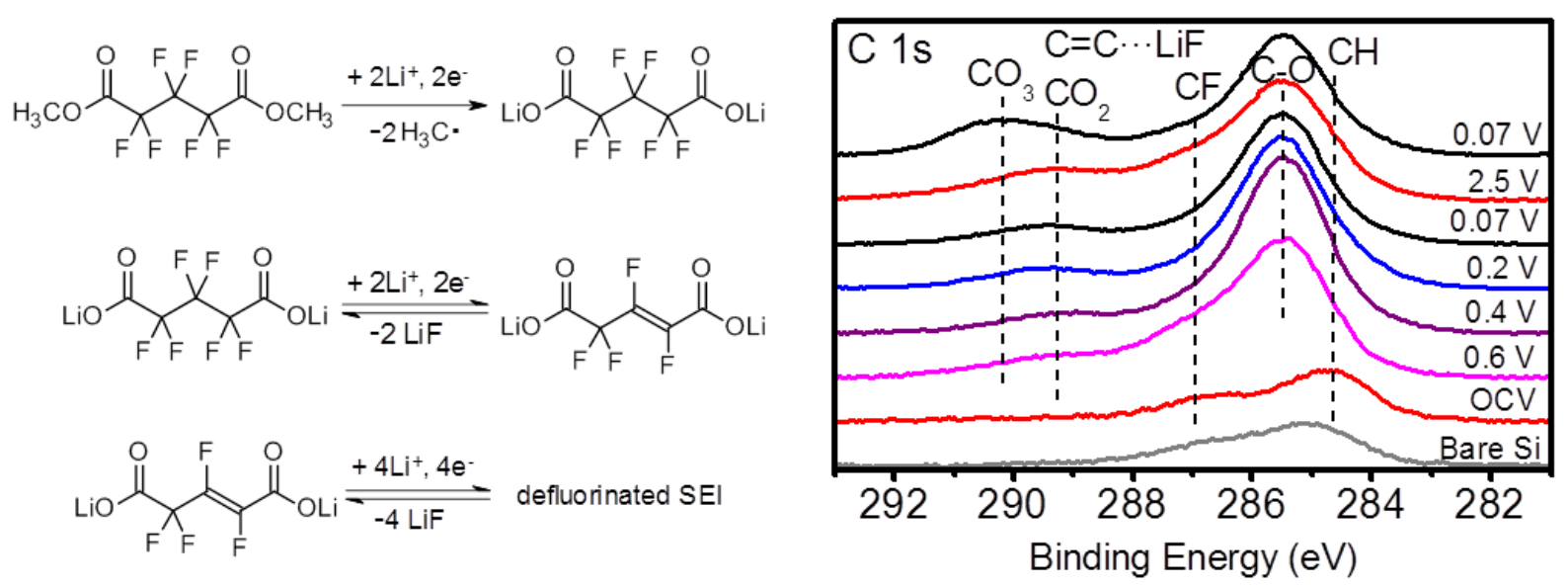

Binding Energy (eV) 
Figure 1.<smiles>COC(=O)C(CC(F)(F)F)(C(=O)O)C(=O)OC</smiles>

PFnM

$(n=4,7,9)$<smiles>COC(=O)[14CH2][14CH2][14C](=O)[14C](=O)OC</smiles>

$\mathrm{PF5M}_{2}$

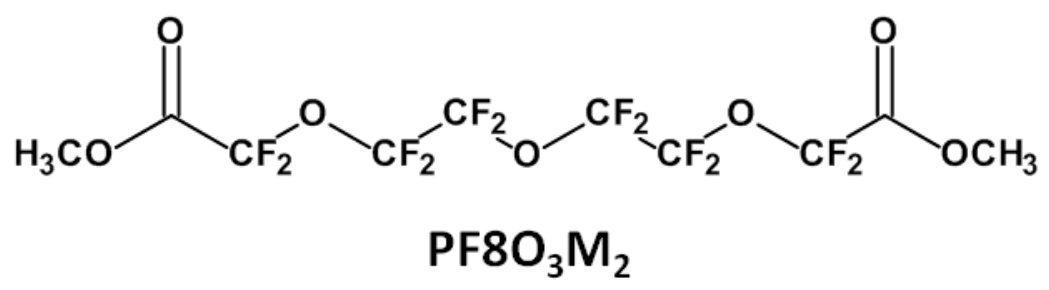


Figure 2.

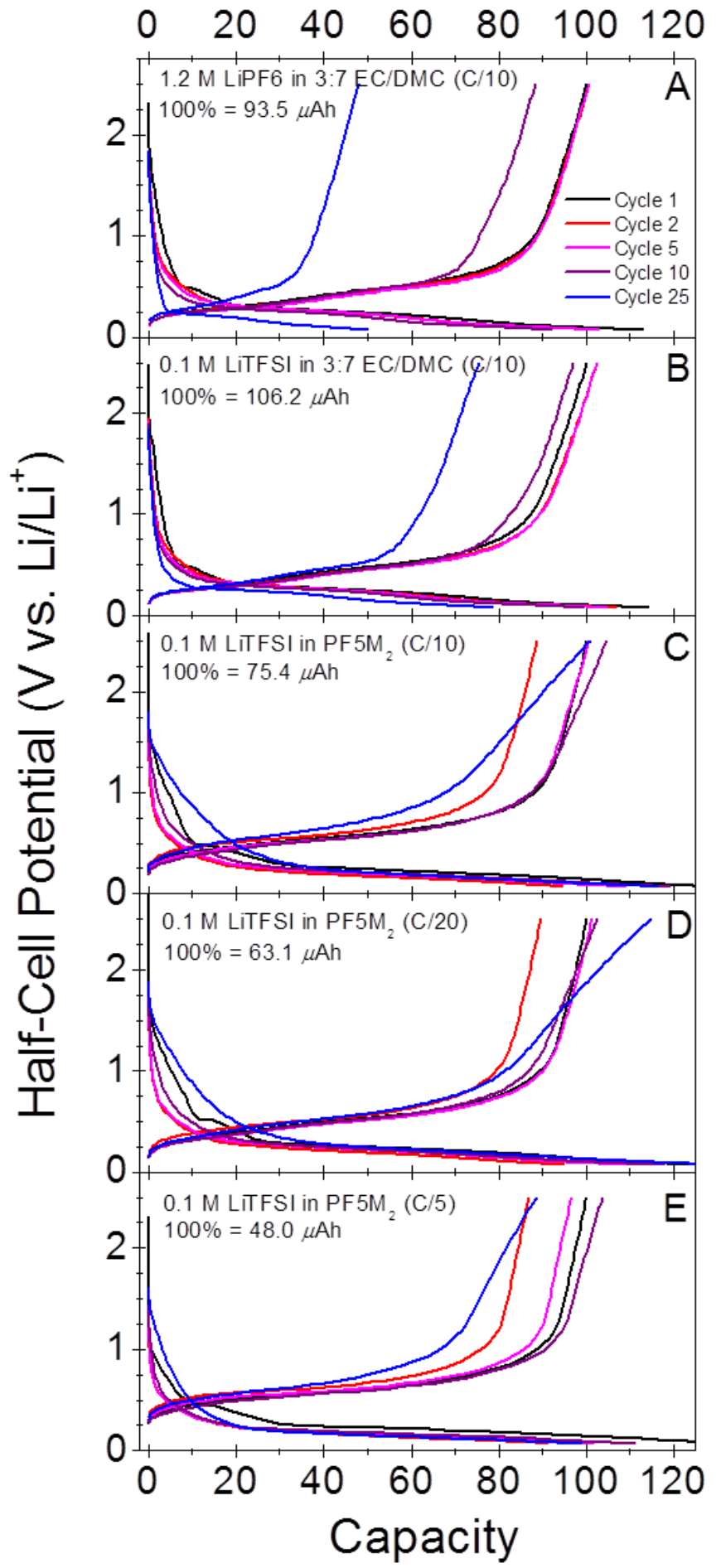

(\% first delithiation)

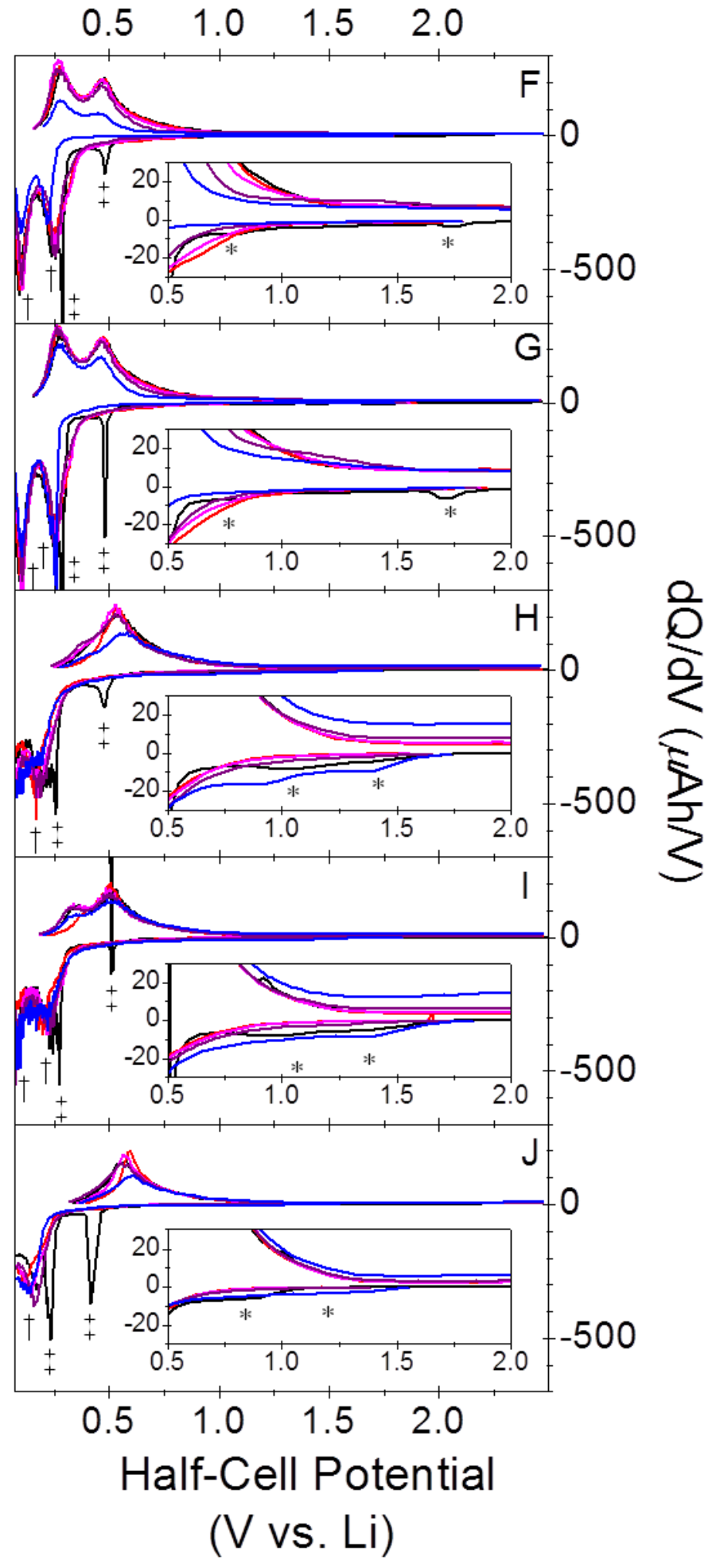


Figure 3.

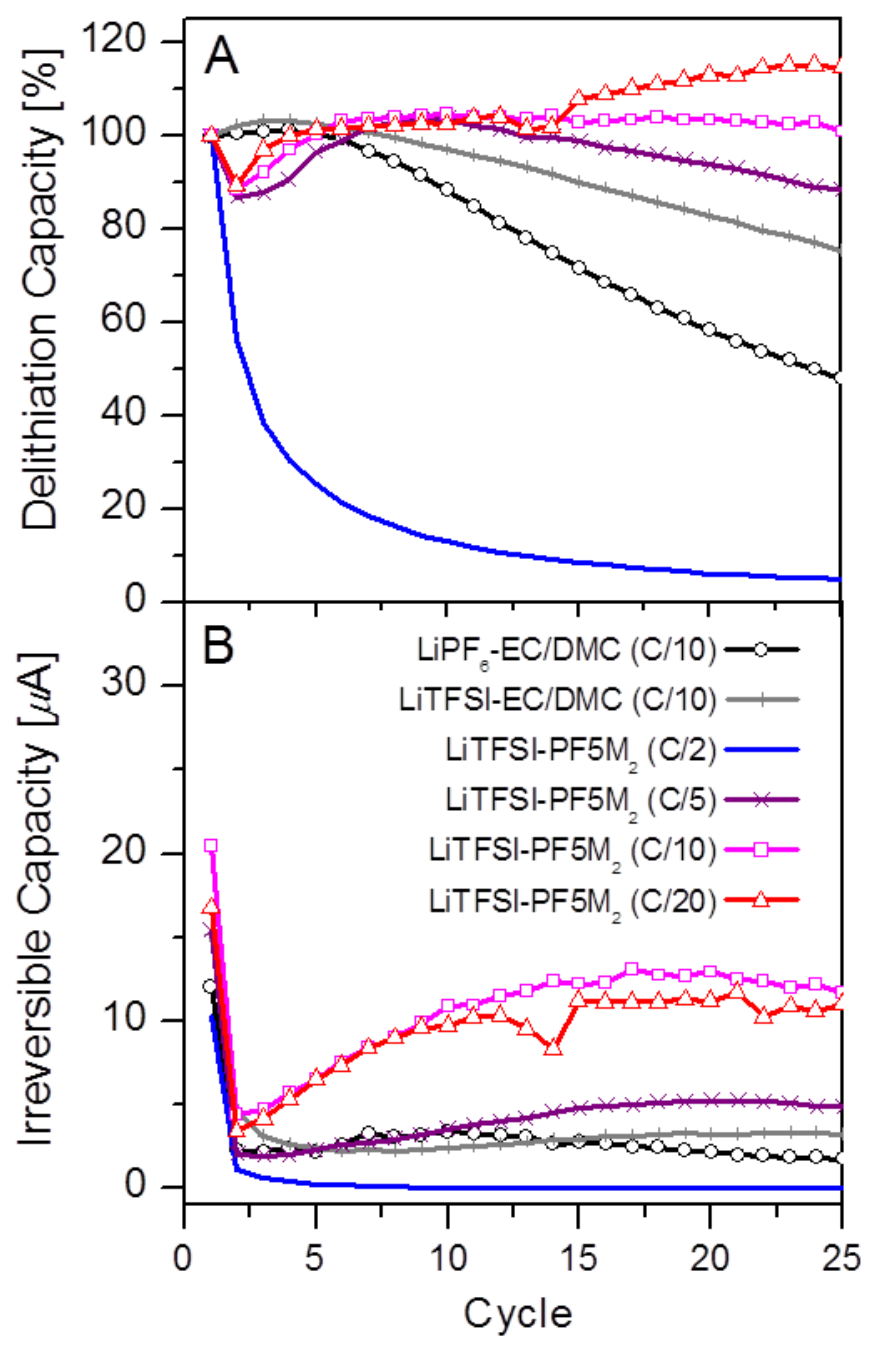


Figure 4.

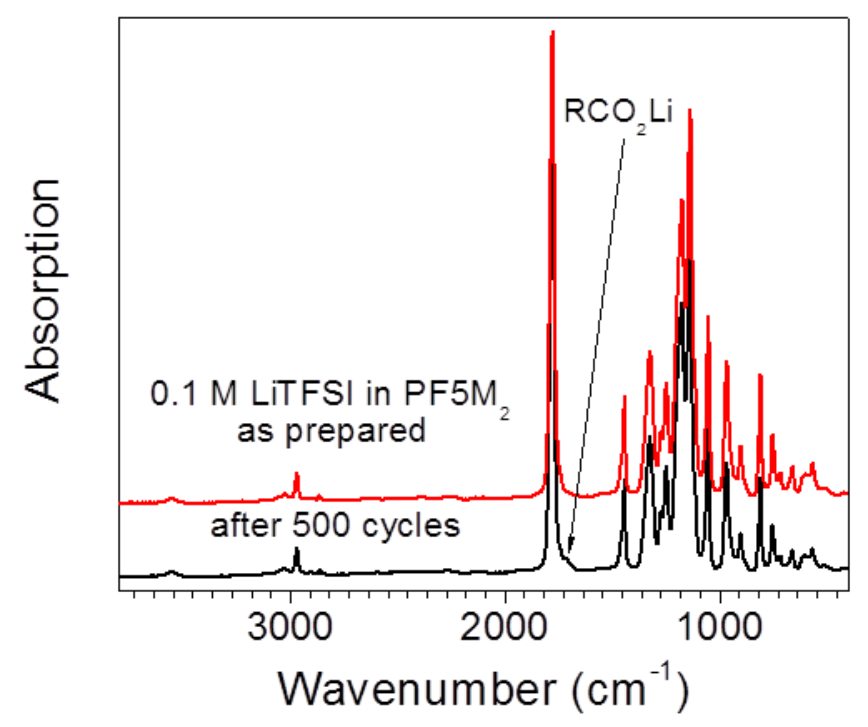


Figure 5.
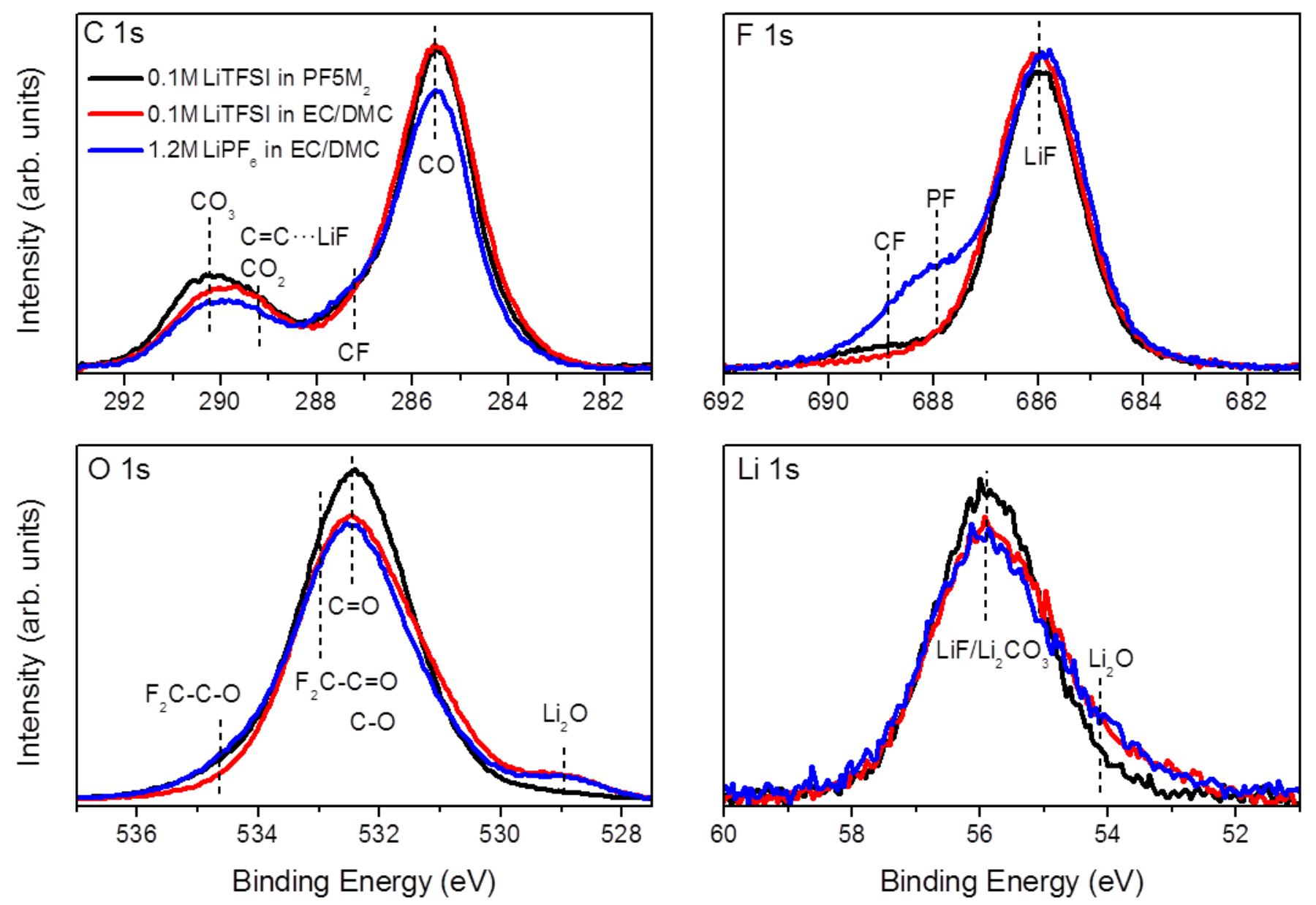
Figure 6.
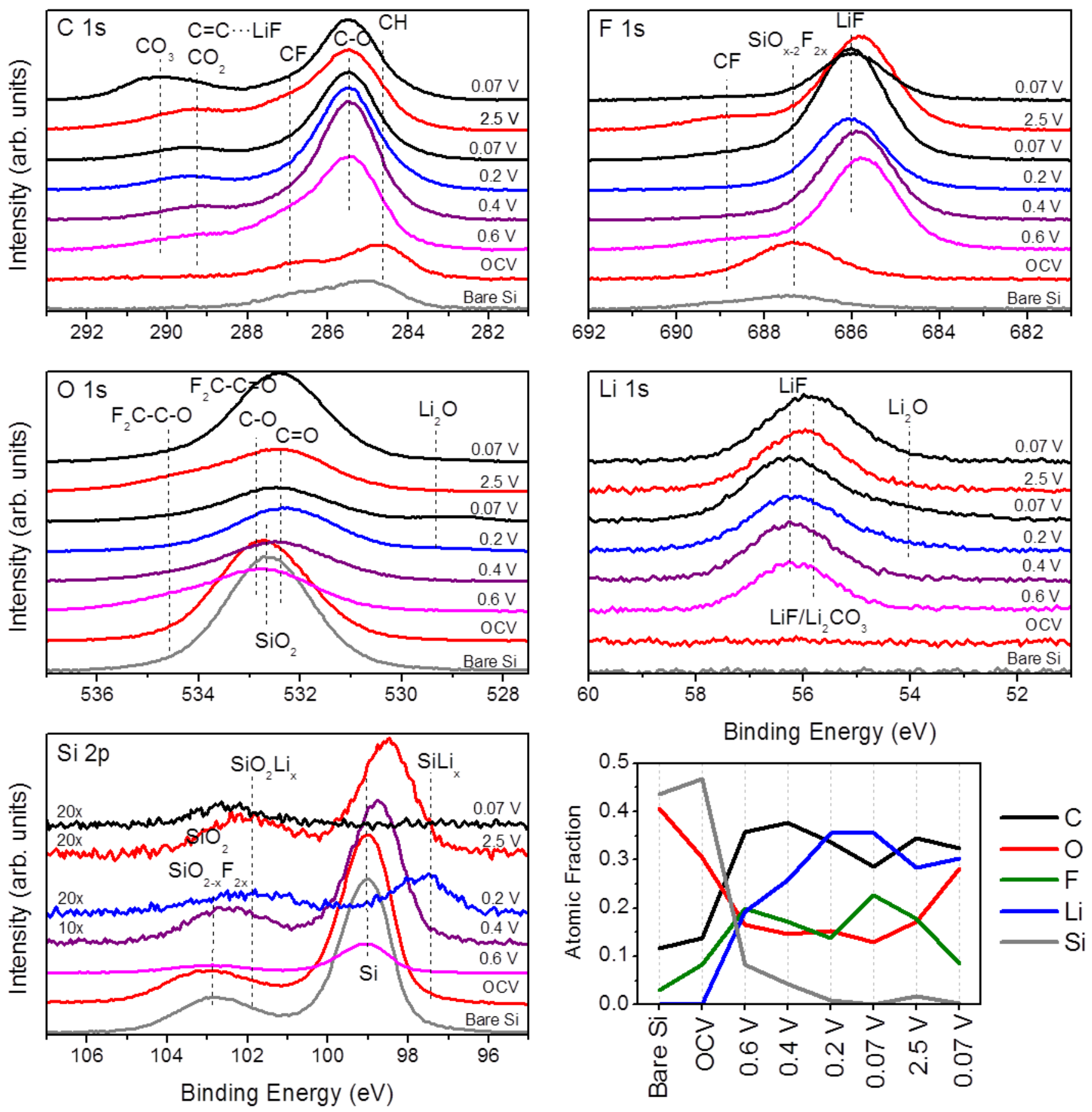
Figure 7.

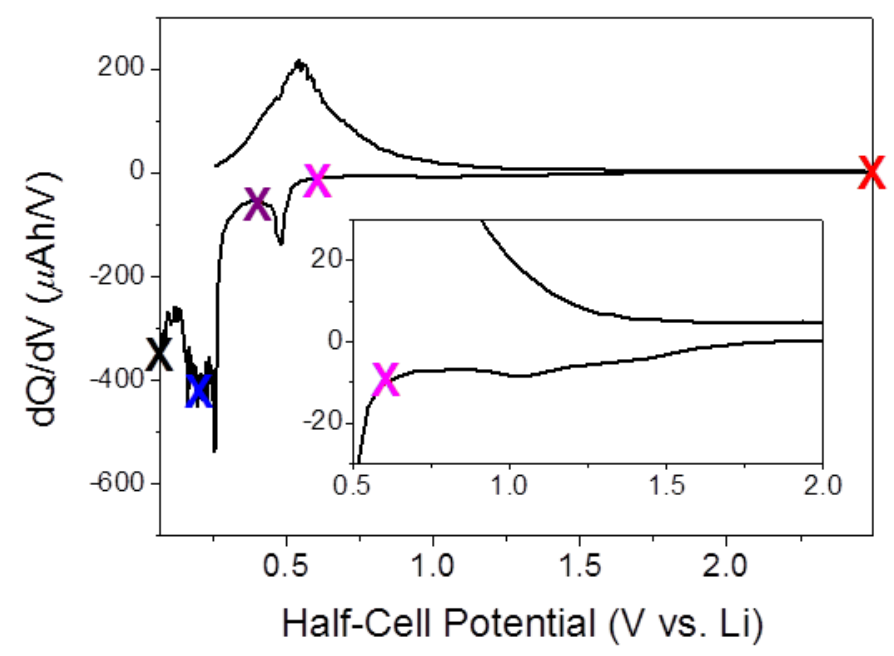


Schematic 1

$$
\underbrace{\mathrm{HCl}}_{-2 \mathrm{H}_{2} \mathrm{O}}=\mathrm{CH}_{\mathrm{F}}^{\mathrm{O}}
$$


Schematic 2.<smiles>COC(=O)C(F)(F)C(F)(F)C(F)(F)C(=O)OC</smiles> 
Schematic 3.

$\underbrace{\mathrm{O}}_{-2 \mathrm{LiF}}$ 
Fig. 1. Perfluorocarboxylate esters investigated in this work.

Fig. 2. Electrochemical cycling results on Si thin film electrodes. (A-E) Charge-discharge curves for investigated electrolytes at several cycling rates, normalized to initial delithiation capacity to account for fluctuations in Si thin film thickness, and (F-J) their respective differential capacity curves with an expanded inset to show SEI formation. Reduction peaks related to reversible lithiation $(\dagger)$, irreversible lithiation (\$), and SEI formation (*) are labeled.

Fig. 3. Capacity fade in Si thin film electrodes: (A) normalized delithiation capacity and (B) absolute irreversible capacity (lithiation capacity - delithiation capacity). The anomalous capacity drop at cycles 13 and 14 in the PF5M $\mathrm{M}_{2}$ electrolyte $(\mathrm{C} / 20)$ is due to a decrease in electrolyte conductivity caused by a drop in ambient temperature.

Fig. 4. IR absorption spectra of the PF5M $\mathrm{M}_{2}$ electrolyte before and after 500 cycles at $\mathrm{C} / 5$. All peaks are attributable to $\mathrm{PF}_{5 \mathrm{M}}$ in both spectra except for the small shoulder in the cycled electrolyte at $1700 \mathrm{~cm}^{-1}$, attributed to the carbonyl stretch in the corresponding lithium carboxylate.

Fig. 5. High-resolution XPS of lithiated (0.07 V) Si electrodes after 7 (1.2 $\mathrm{M} \mathrm{LiPF}_{6}$ in EC/DMC and 0.1 M LiTFSI in EC/DMC) and 2 (0.1 M LiTFSI in EC/DMC) lithiations with nominal peak identifications.

Fig. 6. High-resolution XPS and atomic fractions of Si electrodes cycled with $0.1 \mathrm{M} \mathrm{LiTFSI}$ in PF5M 2 at the various SOCs shown in Figure 7. A delithiation and second lithiation step was performed to determine SEI stability.

Fig. 7. Differential capacity curve with SOCs labeled for (and color-coded to match) XPS data.

Scheme 1. Esterification of perfluoroglutaric acid ( $\left.\mathrm{PF}_{2} \mathrm{~A}_{2}\right)$ to form dimethyl perfluoroglutarate $\left(\mathrm{PF}_{2} \mathrm{M}_{2}\right)$.

Scheme 2. Electrochemical de-esterification of PF5M 2 .

Scheme 3. Electrochemical defluorination of lithium perfluoroglurate.

Table 1. Electrolyte conductivity as determined by impedance spectroscopy. 